\title{
Una aproximación a la modernidad. La convivencia en tanto posibilidad de enseñanza escolar.
}

An approach to modernity. Coexistence as a posibility of school education.

DOI: 10.32870/sincronia.axxv.n79.27a21

\section{Eduardo Solano Vázquez}

Doctorado en Educación. Universidad de Guadalajara (MÉXICO)

CE: pumalibro@hotmail.com / ID ORCID: 0000-0002-3038-0142

Esta obra está bajo una Licencia Creative Commons Atribución-NoComercial 4.0 Internacional

Recibido: 02/03/2020

Revisado: $22 / 10 / 2020$

Aprobado: $10 / 11 / 2020$

\section{RESUMEN}

El texto aborda el asunto de la modernidad, sus consecuencias y la manera en que la ética y la escuela pueden contribuir en la orientación de la convivencia en este momento moderno. En este sentido, si bien la modernidad ha ocasionado el desencanto, en el sentido de que la razón instrumental se convirtió en el parámetro del mundo, al grado de tecnificarlo en extremo, eso no tiene que llevar a la renuncia de la razón, la libertad y la convivencia.

La referencia a la ética y la escuela, se hace para que, a través de ellas, se perfile la convivencia en esta etapa de la modernidad. En este sentido, el pensamiento se encuentra ceñido a la añoranza, pero ella no puede ser desestimada, pues, aunque no responde a una racionalidad tecno-científica, no por ello deja de ser razonable. En este sentido, es importante ser razonable, sobre todo, en este momento de la modernidad en donde lo que predomina es el desencanto, el absurdo y el vacío.

Palabras Clave: Modernidad. Razón. Ética. Escuela. 


\section{ABSTRACT}

The text addresses the issue of modernity, its consequences and the way in which ethics and school can contribute to the orientation of living together in this modern moment. In this sense, although modernity has caused disenchantment, in the sense that instrumental reason became the parameter of the world, to the degree of technifying it in the extreme, that does not have to lead to the renunciation of reason, freedom and living together

The reference to ethics and school, is made so that through them, coexistence in this stage of modernity is outlined. In this sense, thought is limited to longing, but it cannot be dismissed, because although it does not respond to a techno-scientific rationality, it does not cease to be reasonable. In this sense, it is important to be reasonable, above all, in this moment of modernity where what predominates is disenchantment, absurdity and emptiness.

Keywords: Modernity. Reason. Ethics. School.

"Al margen de que seamos o no modernos vivimos en una sociedad moderna".

(Bauman, 2009)

\section{Introducción}

El texto se avoca al asunto de la modernidad y al modo de ser que despliega en el tiempo-espacio social e histórico. Asimismo, también se aborda la ética y la escuela, lo cual permite pensar la convivencia entre el yo-otro en esta etapa de la modernidad. Ahora bien, la convivencia entre el yootro es una aspiración importante en términos éticos, pero que puede ser ridiculizada mediante el pensamiento desencantado. Así pues, se confía en que el pensamiento recobre su capacidad crítica, para que desmonte al absurdo y al vacío, los cuales dejan sin posibilidad al ser situado social e históricamente, para pensar y actuar en el presente.

Es importante señalar en qué consisten cada uno de los apartados que conforman al escrito. Así pues, el primer apartado da cuenta de la modernidad en tanto estructura cultural-civilizatoria, misma que se sostiene en la razón, la secularización del tiempo, la libertad, la ciencia y el progreso. 
La razón moderna tiene la característica de organizar el espacio, lo cual quiere decir que, no se dejan cabos sueltos. Por otro lado, es oportuno expresar que, la modernidad es la promesa de hacer progresar al género humano.

El segundo apartado trata de la crítica que se vierte a la modernidad, en la medida que su promesa de emancipación fue dejada de lado, y el progreso se limitó a la tecnificación del mundo. En este sentido, se habla del desastre ocasionado por la razón instrumental, lo cual no quiere decir que, la reconstrucción del mundo social e histórico pueda darse a través del irracionalismo, por el contrario, es cardinal recuperar la razón y trasladarla hacia su dimensión crítica.

El tercer apartado da cuenta de la manera en la que, la razón puede coadyuvar a la convivencia entre el yo-otro. Además, se considera que a través de la razón en su derivación crítica se puede soterrar al pensamiento que sólo ve medios y no fines, pues esta manera de pensar hace inviable la convivencia entre el yo-otro, en la medida que su relación se agota cuando se considera que ya no se obtiene alguna utilidad. Ahora bien, la razón crítica piensa la relación entre el yo-otro con la intención de establecer la convivencia, por lo tanto, se requiere que el yo-otro se asuman en tanto fin en sí mismo.

El cuarto apartado recoge las reflexiones dadas en las tres primeras partes del escrito para abordarlas a través de la escuela. En este sentido, hay que tomar en cuenta que, la escuela es una institución moderna, ella también tiene las proezas y los absurdos de la modernidad en tanto estructura cultural-civilizatoria. Asimismo, si en este escrito se considera que la escuela todavía puede dar de sí para enseñar y detonar la convivencia entre el yo-otro, es porque se confía en que la escuela puede reconstruir la promesa de emancipación y libertad que la modernidad postuló en sus inicios, evidentemente, tales principios tienen que resignificarse, para que hagan sentido en esta etapa de la modernidad.

El último apartado es la conclusión del texto, en él se insiste en no abandonar la razón, pero sí en deslindarse de la razón instrumental y de los reduccionismos científicos, políticos, sociales. En esta apuesta por la razón crítica y la convivencia entre el yo-otro afianzada por la escuela, se trasluce la añoranza, aquí la pregunta no puede evadirse, si es que se quiere ser consecuente con la 
razón crítica ¿La añoranza puede ser el antídoto para eliminar el desencanto? Ya no hay retorno, no se puede recuperar el sentido inicial de la modernidad a cabalidad, pero tampoco se puede regresar a la era tribal. En este sentido, lo que queda es reconstruir el pensamiento-acción en aras de poder habitar el presente. Es decir, se tiene que ocupar el tiempo social e histórico, a su vez, se tiene que actuar, para que en él la relación entre el yo-otro esté encaminada a ser de larga duración, que se conviva y se discrepe, pues los acuerdos que no se discuten uniformizan y reducen el pensamientoacción. Asimismo, mientras se genera una institución pedagógica adecuada a esta etapa de la modernidad, es indispensable confiar en la escuela y su capacidad de enseñanza. Ésta es histórica, por lo tanto, el sentido de la escuela no está ceñido a lo inmutable y puede coadyuvar a reconfigurar y habitar el presente.

\section{La modernidad: estructura cultural-civilizatoria}

La modernidad seculariza el tiempo-espacio, por lo que requiere una moral cívica para amalgamar, justificar y dar sentido a las acciones individuales-sociales que se suscitan en ella (Touraine, 1994). En este sentido, el tiempo-espacio de la modernidad tiene las condiciones para sostener al ideal de progreso. Asimismo, la modernidad es una totalidad estructurada, en otras palabras, la ciencia, la empresa, la técnica; van en busca del progreso y consideran que todo es susceptible de ser mejorado (un mejoramiento del mundo cuasi perpetuo).

La secularización del tiempo-espacio y el ideal de progreso van a propiciar que, en la modernidad la noción de experiencia histórica tenga cabida. Así pues, lo finito va a soterrar a lo trascendente y las esencias no son requeridas en un estadio cultural-civilizatorio que le da prioridad a la razón en tanto que ella es capaz de argumentar únicamente en relación a lo que observa. Por otro lado, la modernidad ve en la escuela a la institución adecuada para promover sus principios: razón, ciencia, progreso:

La educación del individuo debe ser una disciplina que lo libere de la visión estrecha, irracional, que le imponen sus propias pasiones y su familia, y lo abra al conocimiento racional y a la participación en una sociedad que organiza la razón. La escuela debe ser un 
lugar de ruptura respecto del medio de origen y un lugar de apertura al progreso por obra del conocimiento y de la participación en una sociedad fundada en principios racionales. (Touraine, 1994, p. 20)

La modernidad es imposible sin individuos racionales y libres, mismos que se despojen de la costumbre y se deslinden de sus comunidades de origen, puesto que el pacto social moderno se funda en las leyes, las cuales son impersonales (universalizables) y buscan ser benéficas para el individuo y la sociedad. En este sentido, la modernidad promueve una igualdad ante la ley y también una democracia a nivel gubernamental. Así pues, el igualitarismo moderno desplaza a la jerarquización de la sociedad medieval, misma que les deba preferencia a los reyes, príncipes y sacerdotes.

La razón moderna se va a decantar por organizar el mundo a través de las funciones (Löwy y Sayre, 2008). En ese sentido, la razón moderna es operativa, por lo que este tipo de razón no es contemplativa, sino instrumental. Así pues, es necesario que el individuo y la sociedad intervengan con sus acciones en la construcción del proyecto moderno y, por lo tanto, en la consumación del ideal de progreso.

El proyecto moderno representa el optimismo frente a un contexto cultural-civilizatorio que, todavía tenía las secuelas de la edad media. Sin embargo, el individuo no demora en percatarse de que la razón, la ciencia y la técnica son insuficientes para conseguir materializar el ideal de progreso, pero no desiste en su labor de construir y alcanzar hasta donde sea posible el progreso y diseminarlo en los ámbitos sociales-culturales. En este sentido, el progreso contiene elementos utópicos, por más que se sostenga en una razón que organiza y hace funcionar a la sociedad como si fuese una máquina. Por otro lado, es una necedad sostener que, en la modernidad no se han dado manifestaciones de progreso:

Es innegable no solo que muchos de los desarrollos de la modernidad son irreversibles, tanto en el nivel del individuo como de la sociedad o de la economía, sino también que algunos de ellos representan adquisiciones importantes para el progreso histórico y 
contribuciones a la plenitud- aún por alcanzarse- del género humano. (Löwy y Sayre, 2008, p. 244)

La ciencia y la técnica moderna, también se relacionan con el modo de producción capitalista. En este sentido, la ciencia y la técnica tienen que producir mercancías. Así pues, la razón se mide con la regla de la utilidad, por lo cual, el saber que no es capaz de ser útil para organizar la sociedad o para robustecer el modo de producción capitalista, se vuelve irrelevante y obsoleto.

En la modernidad no es suficiente con tener conciencia histórica, además ella no se puede medir. Es decir, se carece de criterios para establecer quién tiene más o menos conciencia histórica. Sin embargo, la experiencia histórica del individuo y la sociedad sí puede ser observada y medida a través del desarrollo de su sistema jurídico, económico y, sobre todo, de sus aportes científicos y tecnológicos. La razón moderna confía en lo visible, pues lo que se ve, es lo que puede ser modificado-mejorado, para satisfacer las necesidades del individuo, la sociedad y la economía.

Si bien es cierto que la modernidad tiene una tendencia hacia lo nuevo, de ninguna manera puede decirse que, ella crea desde la nada una civilización. En este sentido, es oportuno indicar que, la modernidad también lee y se apropia de una tradición (la greco-latina), pero la adecua al contexto de la sociedad que se desenvuelve dentro del ámbito de la industrialización (Giddens, 1994).

La razón moderna que ha suplantado la idea de un Dios omnipresente y que además confía en la libertad del individuo y la sociedad, no va a dejar cabos sueltos, por ello va a vigilar al individuo y la sociedad a través de las escuelas, los hospitales. De esta manera, las acciones individuales y sociales no pueden ser de una libertad absoluta, pues de ser así, se corre el riesgo de que el pacto social se disuelva. Sin un pacto social, el progreso se vuelve superfluo, puesto que éste es la manifestación racional de una experiencia histórica. Asimismo, no debe olvidarse que, la modernidad es una totalidad estructurada, aunque no necesariamente armónica:

Sugiero que deberíamos sustituir esas imágenes de la modernidad por las de juggernautla imagen de una desbocada máquina de enorme poderío a la que, colectivamente como 
seres humanos, podemos manejar hasta cierto punto, pero que también amenaza con escapar de control, con lo que nos haría añicos. El juggernaut aplasta a aquellos que se le resisten, y si a veces da la impresión de mantener un firme equilibrio, hay momentos en los que vira erráticamente en direcciones imprevisibles. (Giddens, 1994, p. 132)

El estadio cultural-civilizatorio moderno puede dar muestras de decadencia. Sin embargo, hay que tener presente que, la modernidad surgió como un movimiento de ruptura con lo establecido (Touraine, 1994). En ese sentido, la modernidad gesta su autodestrucción para reinventarse. Es decir, las ideas rectoras de la modernidad: razón, libertad, progreso; se adecuan a la situación histórica. Ahora bien, si se considera a la modernidad como una máquina, pues es oportuno pensar que, ella también se ajusta para seguir funcionando y cuando definitivamente caduca, sirve como modelo para la creación de una máquina más eficaz.

Si la modernidad es un estadio cultural-civilizatorio que todavía persiste, se debe a que tiene la pericia para mostrarse como un modo de ser. En este sentido, su experiencia histórica no sólo se sostiene en la razón, la ciencia y la economía; también tiene en su modo de gobernar la sociedad a uno de sus baluartes. Ahora bien, la democracia es formalmente incluyente, pues tiende a ciudadanizar a cada uno de los individuos, independientemente de sus condiciones socioeconómicas o de su identidad étnica.

En la modernidad se da el fenómeno de la división social del trabajo, lo cual requiere una especialización para las actividades económicas, por lo que ya no es suficiente con ser aprendiz en un taller en tanto que el trabajo, también se sostiene en la razón científica, de ahí que un requisito básico es que todos sepan leer y escribir. Por otro lado, la sociedad moderna es cuantitativamente grande, por lo cual, el Estado se convierte en la institución central de la política (Gellner, 2001). Asimismo, no hay cabida para una política que dé cuenta de las diferencias culturales, además, el Estado está conformado por ciudadanos libres que han dejado atrás sus comunidades y costumbres particulares en aras de conseguir la experiencia histórica (universal) que les permita conseguir el progreso. 
El progreso es una aspiración o ideal moderno, pero lo idóneo para la modernidad es que él sea una manifestación real, para que ello sea así, se necesita que la sociedad esté cohesionada, pues el progreso se dificulta en una sociedad fragmentada. En este sentido, uno de los objetivos del Estado moderno, es crear una cultura nacional que permita la consumación del progreso:

El estado nacionalista no sólo es el protector de una cultura, sino también de una nueva, y a menudo al comienzo frágil, economía. (Generalmente deja de interesarle proteger un credo.) En los casos en que una nación moderna nace de lo que antes había sido sólo un estrato -exclusivamente de campesinos o exclusivamente de especialistas urbanos-, el doble interés del estado por hacer de su grupo étnico una nación equilibrada y por desarrollar su economía se convierte en dos aspectos de una sola y única tarea. (Gellner, 2001, p. 146)

La modernidad no es un estadio cultural-civilizatorio inmune a las deficiencias. Sin embargo, este estadio cultural-civilizatorio ha marcado la pauta durante los últimos siglos. Por otro lado, si bien la razón no lo puede resolver todo, tampoco se puede renunciar a ella, porque de hacerlo, se corre el riesgo de caer en el ámbito de lo instintivo, y ahí ya no hay posibilidad para distinguir el bien del mal.

\section{Crítica a la estructura cultural-civilizatoria de la modernidad}

La modernidad surge en el occidente como un movimiento de ruptura, siendo más específicos, el surgimiento se da en la Europa central. Asimismo, un objetivo de la modernidad es universalizar la cultura europea. Sin embargo, el progreso cultural-civilizatorio fue absorbido por la propagación del sistema económico, éste sí ha llegado más allá del suelo europeo (Echeverría, 2008). En este sentido, una de las críticas a la estructura cultural-civilizatoria de la modernidad, se vierte hacia el progreso técnico y económico de la sociedad, en la medida que propician la gestación de la desigualdad socio-económica. 
El pensador Walter Benjamin hace uso de la metáfora, de esta manera, le es posible pensar a la modernidad con la imagen de un sistema de espejos, mismo que es productor de ilusión (Benjamin, 2008). En este sentido, el progreso económico y técnico es una ilusión, pero también es una catástrofe, misma que se manifiesta en la vida individual y social del hombre. La exclusión social es una catástrofe, porque los que la padecen, se les instaura fuera de la historia:

El ángel de la historia debe tener ese aspecto. Su rostro está vuelto hacia el pasado. En lo que para nosotros aparece como una cadena de acontecimientos, él ve una catástrofe, que arroja a sus pies ruina sobre ruina, amontonándolas sin cesar. El ángel quisiera detenerse, despertar a los muertos y recomponer lo destruido. Pero un huracán sopla desde el paraíso y se arremolina en sus alas, y es tan fuerte que el ángel ya no puede plegarlas. (Benjamin, 2008, p. 44)

La modernidad es una máquina que arrasa, además, los que le oponen resistencia son llevados a la nada (Giddens, 1994), y estar en la nada implica carecer de tiempo-espacio, lo cual imposibilita alcanzar la experiencia en la historia, misma que tiende hacia el progreso. Es decir, para ser en la modernidad, es necesario que se enarbolen y se practiquen los principios modernos: razón, ciencia, técnica, libertad. Empero, estos principios también han sido apropiados por el capitalismo, en ese sentido, no basta con hacer uso de la razón y la libertad en sí mismas. En otras palabras, la razón y la libertad carecen de valor en sí, en el entendido de que han sido llevadas al ámbito de lo instrumental, de ahí que, si tienen cabida en la modernidad, es porque se extrae de ellas alguna utilidad. Asimismo, la razón y la libertad se deprecian en un estadio cultural-civilizatorio que sólo las valora bajo el criterio de la utilidad económica.

El tiempo-espacio sin una voz que lo nombre carece de significado. Ahora bien, el tiempoespacio moderno tiene la impronta del progreso, pues el pensamiento y el ojo del hombre moderno expresan y ven progreso por doquier, de ahí que hasta los salvajes pueden ser incorporados a la civilización, siempre y cuando aprendan a comportarse. 
El pensador Jacques Rancière aduce que, el tiempo en el cual el hombre realiza sus actividades y se apropia del espacio es una narración (Rancière, 2017), para él cualquier hombre capaz de hacer una narración puede apropiarse del tiempo-espacio. En este sentido, Rancière va a realizar una crítica al tiempo moderno, en la medida que éste se hace pasar como el non plus ultra:

La racionalidad causal de la vinculación temporal entre acontecimientos está atada a una distribución jerárquica de las temporalidades, que es una distribución de formas de vida [...] La modernidad se vincula con la dimensión vertical del tiempo, lo que implica su rol en la distribución de lo sensible [...] El tiempo es una forma de distribución de los seres humanos, un modo de división entre dos formas de vida. (Rancière, 2017, p. 15 y 42)

El tiempo moderno es más que una concepción, puesto que, con su representación del mundo, también consigue estipular cómo ha de ser la experiencia en la historia. Asimismo, una razón que sólo se fía de lo que observa, no puede prescindir de la experiencia, pues ésta puede ser mejorada o en un caso extremo desechada, sobre todo, cuando ya no dice algo útil respecto al mundo. En la era de lo útil se corre el riesgo de ser un desecho en el próximo proceso.

La crítica a la estructura cultural-civilizatoria de la modernidad no tiene sentido y potencia, si lo que pretende es borrar todo lo que lleva el rótulo de la modernidad. En este sentido, renunciar a la razón es un error, puesto que lleva al ámbito de lo meramente instintivo. La crítica hacia el tiempo y el progreso moderno no pretende regresar al pasado, ni construir desde la nada una civilización, su radicalidad consiste en recordar que, la razón y la acción humana es de suyo limitada, por lo tanto, en el afán de querer rebasar el límite, pues la razón y la acción humana caen en el absurdo. En este sentido, la crítica busca develar los absurdos de la modernidad.

La razón no sólo tiene que ser usada para organizar el mundo, sino también para esclarecerlo hasta donde sea posible (Rancière, 2010). Es decir, no es suficiente con la razón instrumental, también se requiere la razón crítica, para que contenga el exceso, mismo que se manifiesta a través de la tecnificación total del mundo y en la naturalización absoluta del mismo. 
La crítica a la estructura cultural-civilizatoria de la modernidad es un modo de "posicionarse" razonablemente en torno a los malestares que ocasiona y ha ocasionado la modernidad en el ámbito socio-político: la desigualdad, la exclusión. Sin embargo, una crítica que busca negar la modernidad o que pretende erigirse como el único modelo de crítica respecto a la modernidad, lo que propicia es una depreciación de la crítica y eso no coadyuva en el esclarecimiento de las palabras y las cosas:

No hay ningún pasaje teórico de la crítica modernista al nihilismo posmoderno. Sólo se trata de leer en otro sentido la misma ecuación de la realidad y de la imagen, de la riqueza y de la pobreza [...] El problema no es oponer la realidad a sus apariencias. Es construir otras realidades, otras formas de sentido común, es decir, otros dispositivos espacio-temporales, otras comunidades de las palabras y las cosas, de las formas y de las significaciones. (Rancière, 2010, p. 48 y 102)

La modernidad ha construido una realidad que ha condicionado al pensamiento y la acción humana. En otras palabras, la manera en la que se piensa y se actúa en el estadio cultural-civilizatorio moderno va dejando la señal de su presencia, por eso, aunque las generaciones se van relevando unas a otras, la modernidad no cesa de manifestarse. En este sentido, se puede decir que, la astucia de la modernidad ha radicado en lo siguiente: la modernidad en su condición de totalidad estructurada, les da cabida a los desencantos de la cultura y la civilización, siempre y cuando surjan y perezcan en ella, pues de esa manera tiene las cosas bajo control. Asimismo, la modernidad hizo trisas la idea de un mundo creado por Dios, pero no renunció a la idea de la creación, sólo que ahora ella es la encargada de hacer lo que antes se consideraba ocasionado por la divinidad. En este sentido, la modernidad es una utopía en donde la razón y el progreso fungen como las palancas de la historia.

El saber dejo de ser exclusivo de los monasterios, pues no estaban constituidos para democratizarlo. No se debe olvidar que, en la modernidad es básico que todos sepan leer y escribir. Así pues, el saber en la modernidad está bajo la potestad de la escuela (Horkheimer, 1973), no es 
una nimiedad que el saber haya sido arrancado del monasterio, para colocarlo en la escuela. Es decir, la modernidad requería crear una institución que representará y defendiera su proyecto en torno al progreso del mundo.

La ciencia no surge en la modernidad, pero en ella se deslinda de su dimensión esotérica y enigmática, ya no se trata de una ciencia revelada sólo a los elegidos. En la era de la democracia, la ciencia puede ser desarrollada por creyentes y ateos. Sin embargo, lo loable de democratizar la ciencia, también trajo consigo el cientificismo, es decir, considerar que todo depende de la ciencia o que el mundo en su totalidad es ciencia, dejando a la deriva o subordinando al método de la ciencia a otras formas de acceder al conocimiento (la filosofía, el arte):

Al igual que toda fe establecida, también la ciencia puede ser utilizada al servicio de las fuerzas sociales más diabólicas y el cientificismo no es menos estrecho que la religión militante [...] La ciencia debería esperar del pensar filosófico, tal como lo exponen ya sea los filósofos, ya los científicos, que rinda cuentas acerca de la naturaleza de la verdad, en lugar de simplemente cantar loas a la metodología científica como definición suprema de la verdad. (Horkheimer, 1973, p. 82 y 84)

La modernidad ha propiciado que la valoración del mundo se rija bajo el parámetro de lo útil, lo anterior es válido tanto para el ámbito de la ciencia como para el de las relaciones sociales. Así pues, lo que no es productivo es objeto de desecho, pareciera que eso no afecta al hombre y su manera de posicionarse en el mundo. Sin embargo, cuando las cosas y los seres vivos (incluido el hombre) sólo tienen valor por lo útiles que son, pues invocar a la verdad se torna un sinsentido, es más, en un mundo que está normado por la utilidad, la verdad pierde significado. Asimismo, donde no hay verdad, pululan las opiniones, mismas que erigen pequeños imperios y hacen difícil el diálogo, la comunicación; en suma, la convivencia intersubjetiva y social. 


\section{Razón y convivencia en la modernidad}

El uso de la razón le da viabilidad al manejo de las pasiones, no las elimina, pero con contenerlas es suficiente (Spinoza, 2011). No es trivial buscar la mesura, sobre todo, si se considera que el hombre no sólo está consigo mismo, sino que también está con otros hombres en sociedad. En otras palabras, si bien el hombre también es un ser pasional no lo puede ser en todo momento, puesto que vive en sociedad y ésta para no perderse en la inmediatez tiene que establecer unas reglas para interactuar.

Una de las características de la sociedad es que coacciona, pero cuando los que conforman la sociedad hacen uso de la razón, pues entienden que la coacción también es para lograr la convivencia. Es decir, si se permitiese realizar todo lo que dictan los apetitos y la voluntad, el convivir sería imposible en tanto que lo que uno quiere, no se asemeja a lo que el otro está queriendo. En este sentido, los apetitos y la voluntad no pueden ser el fundamento de la convivencia, de ahí que es crucial que la razón sea el principio para la vida en común:

Los hombres, digo, no pueden desear nada más excelente para conservar su ser que el estar todos de acuerdo en todas las cosas de tal suerte que las almas y los cuerpos de todos compongan como una sola alma y un solo cuerpo y se esfuercen todos a la vez, por conservar su ser y busquen todos a la vez para sí lo útil común a todos; de lo cual se sigue que los hombres que son gobernados por la razón, esto es, los hombres que buscan lo que les es útil bajo la guía de la razón, no apetecen nada para sí que no deseen para los demás hombres y, por tanto, son justos, leales y honestos. (Spinoza, 2011, p. 194 y 195)

La modernidad dice de sí misma que se basa en la razón, pero ésta se ha inclinado más hacia el cálculo y lo instrumental. Asimismo, el bien común no se dirime entre los que comparten el mismo espacio histórico y social, pues la conversación se hace imposible en sociedades multitudinarias, en ellas lo que prevalece es el anonimato. Empero, no se puede olvidar que, conseguir un acuerdo respecto al bien común coadyuvaría a que la razón recupere su talante crítico, ya que encauzaría al individuo y a la sociedad hacia un contexto cultural-civilizatorio en donde la ciencia y la técnica se 
encuentren al servicio del hombre; en lo que se ha mentado, hay algo de utopía, pero no es el acabose, ya que proyectar otra manera de ser en el mundo desde la dimensión individual y social permite que, el hombre se distinga de otros seres y, sobre todo, se deslinde de un pensamientoacción que por doquier ve medios y no fines.

La vida en sociedad no puede tener sólo como criterio de bienestar al desarrollo científico, tecnológico y económico. Empero, también se sabe que ya no hay retorno, pensar en recuperar formas de vida tribales o ajenas de la influencia moderna, no es más que una perspectiva condicionada por la melancolía y el conservadurismo. Por otro lado, renunciar a una vida en común y a la interpelación, es seguir dándole cabida a la tecnificación del mundo, y también es poner en desuso la responsabilidad del hombre consigo mismo y con lo que lo circunda.

La razón tiene que contribuir a realizar la distinción entre el bien y el mal, para ello se necesitan criterios, los cuales, en la medida de lo posible, tienen que establecerse a través del consenso en referencia al bien común de una sociedad históricamente situada. La distinción del bien y del mal, se tiene que hacer para evitar hacerle daño al otro, pues ello también deviene en desprecio social (Bauman, 2009); en otras palabras, cuando se le hace daño a alguien, éste pierde dignidad ante los ojos de los demás, los cuales lo pueden mirar con compasión, pero no como a un igual:

Ayudarnos unos a otros puede involucrar sacrificios, pero el sacrificio es intrínseco a la moralidad. No importa si el beneficio derivado de este sacrificio llega ahora o en el futuro, o en la otra vida. Lo importante es que he contribuido a la continuidad de ese grupo, por cuyo éxito se mide el bien y la rectitud [...] La moralidad es la asistente de la existencia por la razón que la rige. La moralidad es lo que elegiría un ser razonable en tanto ser y razonable. (Bauman, 2009, p. 55)

La razón crítica irrumpe en el tiempo-espacio que le da prioridad a lo redituable, de ahí que este tipo de razón tiende a ser considerada disfuncional e impropia. Es decir, se oye vetusto mentar al sacrificio, la responsabilidad y también apelar a una razón que, piense más allá de los medios y le dé 
importancia a los fines: el hombre es un fin y no un medio, como apuntó Emmanuel Kant. Sin embargo, ahora el fin requiere esparcirse más allá del hombre y su entorno social, pues dadas las condiciones históricas es insoslayable el cuidado de la naturaleza, pero no como depuración de la conciencia o mero pasatiempo, sino como responsabilidad con el presente y el futuro (con los que viven y los que están por vivir).

El encuentro que pueda darse entre el yo y el otro, no está exento de violencia, suponer que con el hecho de que el yo y el otro se junten en un espacio, van a mejorar de suyo las situaciones y las relaciones intersubjetivas y sociales, es no tener en cuenta que, la convivencia es deseable, pero también un desafío, el cual demanda paciencia y hasta empatía. Asimismo, el convivir se sostiene en la responsabilidad que el yo es capaz de ejercer tanto para sí como para con el otro. En este sentido, la responsabilidad es una digna carga (Levinas, 2008), porque posibilita una convivencia que no requiere la violencia para ser.

La convivencia entre el yo y el otro es ética y socialmente deseable. Sin embargo, una pregunta emerge cexisten las condiciones para que el individuo y la sociedad ya no se rijan únicamente con la regla del utilitarismo? La relación entre yo y el otro no puede reducirse al intercambio, porque cuando alguno de los dos ya no es capaz de dar, pues viene el olvido o en un caso extremo la aniquilación. Asimismo, el encuentro entre el yo y el otro permite mirar el rostro, y cuando se conoce el rostro de alguien ya es difícil considerarlo sólo como medio:

La moralidad tiene un alcance independiente y preliminar. La filosofía primera es una ética [...] No cabe deducir de lo que acabo de decir cualquier subestimación de la razón y de la aspiración de la razón a la universalidad. Tan sólo intento deducir la necesidad de lo social racional tal como yo lo describo. Es extremadamente importante saber si la sociedad, en el sentido corriente del término, es el resultado de una limitación del principio según el cual el hombre es un lobo para el hombre, o si, por el contrario, resulta de la limitación del principio según el cual el hombre es para el hombre. (Levinas, 2008, p. 65 y 69) 
En la realización de la convivencia de los hombres entre sí, lo idóneo sería decantarse por el principio del hombre es para el hombre. Sin embargo, la probabilidad de que eso sea efectivamente así, pues es mínima, porque los hechos indican que con frecuencia los hombres se consideran en competencia, en esa situación, lo que vale es quien tiene más capacidad de adaptarse a las circunstancias. Ahora bien, no todo está perdido, pues como seres razonables y no solamente instintivos, los hombres pueden distinguir el bien del mal, y así, entender que el mal puede ser evitado.

La confianza tiende a terminarse, cuando aquello en lo que se confía no ha dado lo que de él se esperaba. En este sentido, después del optimismo que la razón suscitó (Spinoza, Kant confiaban en que la razón haría mejor al hombre), ahora se está en una situación de desencanto, pues la razón cayó en el irracionalismo, ya que la modernidad abandonó su proyecto crítico (Rivas, 2013). Sin embargo, el desencanto es igual o más contraproducente que el irracionalismo, porque deja que las situaciones pasen, ya que para un desencantado sólo hay vacío, de ahí que la intervención en el mundo, la considere innecesaria.

El desencanto también propicia una suspensión negativa del juicio, lo cual imposibilita la distinción del bien y del mal. Un desencantado también prescinde de los criterios para reconocer en el otro a un ser humano que piensa, anhela, siente. Así pues, el desencanto y la tecnificación del mundo no le dan cabida a la humanidad como expresión de la realidad histórica y social; por un lado, la desencantada renuncia a intervenir y también rehúye al contacto con la humanidad histórica y socialmente existente; por otro lado, la tecnificación considera que la humanidad es un señuelo de infancia e improductivo de suyo:

Debemos comprometernos con un sentido. Pero para que éste sea auténtico, desde un punto de vista humano, debe hacernos volver la mirada hacia el ser humano, a su dignidad y sus derechos inherentes [...] Cuando hablábamos del sentido y su relación con el valor, el ser humano es el criterio de lo valioso; es él quien dota de sentido. Desde un punto de vista secular, el ser humano es lo único sagrado que tenemos y en tanto sagrado es improfanable. (Rivas, 2013, p. 85 y 86 ) 
El pensamiento que expresa nociones como las de humanidad y convivencia puede considerarse sempiterno. Sin embargo, el pensar sabe que la razón, o sea, la capacidad de hacer distinciones y establecer criterios, también puede ser usada para lograr una mejor estancia para el hombre en su condición individual y social. Asimismo, la convivencia no viene inscrita en el ADN, por lo que se requiere una propedéutica de la convivencia, la cual puede ser otorgada por la escuela, pues ésta sigue teniendo credibilidad. Es necesario señalar que, hoy como ayer, la vida humana requiere criterios de convivencia, mismos que permitan realizar la existencia, sin que ésta esté atravesada por la destrucción y la violencia.

\section{Escuela y credibilidad: repensar la convivencia}

La importancia de hacer historia de las ideas, no radica en presentarlas solamente en su secuencia periódica, sino en entenderlas a través del contexto. En este sentido, la escuela tiene elementos eclesiásticos (Noro, 2006), pero los objetivos de la escuela son distintos a los de la iglesia; así, su similitud es en cuanto a formas, pero se diferencian por los contenidos y objetivos. Ahora bien, si los contenidos-objetivos son históricos, todavía se puede tener un mínimo de confianza en la escuela, y así, asignarle la tarea de resignificar a la razón, la libertad, la convivencia, el diálogo; aunque esta tarea requiere del auxilio de la sociedad y sobre todo del hombre, su intervención será primordial en la construcción de sentido que solicita la escuela en esta etapa de la modernidad, la cual continúa conformando y convocando al hombre en su condición individual y social.

La modernidad ha creado sus instituciones, su espíritu inventivo es indubitable y es el que le ha permitido perdurar. Asimismo, la escuela es la prueba fehaciente de que la modernidad también es una cultura pedagógica (Vázquez, 2000), en el sentido de que enseña mediante el método didáctico sus valores. De esta manera, la casualidad no tiene cabida en un estadio-cultural civilizatorio que le da prioridad a la razón.

La escuela es cuestionada porque en tanto institución de la modernidad, también ha priorizado a la razón instrumental. Sin embargo, la escuela todavía mantiene algo de credibilidad y 
es sobre ésta que la convivencia es pensable, y a partir de ahí, se puede reconfigurar la vida en común, pues sin un mínimo de pautas para vivir con otros, todo puede devenir en absurdo y vacío. Sin embargo, la convivencia no es idílica, pues considerar que todos deben estar de acuerdo es reducir al pensamiento y la existencia al conformismo. Ahora bien, hay cuestiones en las que sí debe haber acuerdos: "La legitimidad no se construye por consigna, o la mera presencia de intereses convergentes. Es necesaria para su construcción la mediación de valores y símbolos compartidos" (Vázquez, 2000, p. 184). Así pues, un valor para la vida en común podría ser el respeto por la vida que se despliega en el espacio social e histórico, lo cual quiere decir que, habría que esmerarse para que todos puedan estar sin penurias.

Las preguntas no son infructuosas, por más que no siempre sean acertadas. Ahora bien, cabe preguntar ¿la escuela sigue teniendo sentido? ¿Los objetivos de la escuela sólo tienen que ser acerca del conocimiento científico y tecnológico? La escuela ha educado para perfeccionar al hombre, por lo menos, ese ha sido su primer cometido, considerando que la modernidad es una cultura pedagógica: "La ilustración intentará reemplazar lo sobrenatural por lo natural, la religión por la ciencia, y creerá fervientemente en la perfectibilidad del hombre" (Tello, 2010, p. 1). Quizá en esta etapa de la modernidad, ya no se trata de buscar la perfectibilidad del hombre, sino de buscar al hombre sin más, es decir, que el hombre pueda diferenciarse de la ciencia, la tecnología y la naturaleza, si lo logra, será capaz de encontrarse y de saber lo que es él, con ese saber que no es científico, puede intentar fraguar una vida para sí y también una convivencia ajena de los reduccionismos.

El tiempo socio-histórico es transitivo. Así pues, pensar la convivencia requiere considerar al presente, pero no como pura actualidad, sino como la temporalidad en donde existe y es posible el encuentro entre el yo y el otro. Es decir, si todavía tiene sentido hablar de proyectos de mejora individual y social, éstos tienen que referirse al ahora, pues las alusiones al futuro sólo son ilusiones. Asimismo, la escuela tiene que coadyuvar a garantizar el presente, en el sentido de posibilitar que el hombre se encuentre y, además, asuma su responsabilidad con lo que lo circunda. 
La modernidad y la escuela son una condición particular de la historia (Mariano, Conforti y Casado, 2012). Así pues, la razón no siempre ha estado relacionada con la ciencia y la educación tampoco ha sido exclusiva de la escuela. No obstante, deshacer de manera abrupta a la modernidad y la escuela puede ser contraproducente, en el sentido de no tener referencias para construir la historia y sus sentidos. Por otro lado, la escuela es quizá la última utopía del proyecto de modernidad ilustrada con vocación emancipadora, que aún persiste en la modernidad tardía: "La escuela es moderna pero el contexto es posmoderno" (Mariano, et. al, 2012, p. 360). La escuela ya no puede ser una máquina de educar, en el sentido de buscar homogenizar en su totalidad a los educandos, pero tampoco puede dejar de inculcar ideas que posibiliten la convivencia y la mejora paulatina de ésta. En este sentido, un Robinson, hoy como ayer sólo es un modelo, pero la educación siempre es respecto a alguien históricamente situado.

La convivencia y la vida en común forman parte de los conceptos difusos en tanto que pueden referir a lo esencialista e inalterable, o también, a lo indiferenciado dada la masificación de los seres y las cosas en el capitalismo democrático (Torres, 1997). Empero, si se renuncia a un proyecto de vida en común ya no habrá posibilidad para la igualdad, la diferencia, la libertad; en suma, para la política en sentido lato: "Frente al mercado y la estatización, lo público permite el reconocimiento de lo común y posibilita el desarrollo de lo individual y lo diferente" (Torres, 1997, p. 11). Por otro lado, la escuela puede educar a la razón, para que sus juicios rebasen el ámbito instrumental. Es decir, el sentido de la escuela puede virar, no se puede ser de memoria frágil y olvidar que, ella sabe enseñar; pero ahora su enseñanza tendría como uno de sus objetivos: fomentar la razón crítica, para evitar en la medida de lo posible los reduccionismos, mismos que llevan a lo incomunicable y sin comunicación la convivencia no tiene posibilidad de manifestarse realmente.

Hay un residuo de añoranza en el hecho de pensar que, la escuela eduque en la razón crítica, no sólo para llevar a los pensamientos y las acciones al tribunal de la duda, sino para que posibilite la convivencia y fomente la capacidad de distinguir el bien del mal, con el fin de que la convivencia no sea por mera conveniencia, ya que cuando ésta desaparece, el estar del yo con el otro, pierde su 
motivo. Empero, la añoranza es el preludio de la proyección de lo que se quiere hacer y también de lo que se quiere llegar a ser. Ahora bien, la escuela como institución especializada (Herramienta, 2020) sigue siendo plausible, porque puede colaborar en la clarificación de un objetivo que sea común a cabalidad, pues el riesgo de que el personalismo impere en el establecimiento de lo común está latente, sobre todo, en una época que es laxa en cuanto a los criterios, ya que en la era del mass media la consigna es: todas las opiniones son válidas en sí mismas.

La posibilidad de transformar el mundo no es desestimable, pero la transformación deviene implosión, sino se sostiene en un sentido, es decir, qué pensar y qué hacer ante lo que se considera fallido: "La crisis de la organización no hay que buscarla en el cuestionamiento postmoderno, sino en las promesas que la propia modernidad no cumplió" (Herramienta, 2020, p. 1). Ya no se puede actuar y mejorar el pasado, el pensamiento y la acción son importantes por lo que son capaces de darle al presente. En este sentido, si la libertad y la convivencia han venido siendo funcionalistas, se tiene que intentar pensar y actuar para que la libertad y la convivencia hagan una ruptura con el funcionalismo; pero dar por caducas a la libertad y la convivencia, es hacer apología del vacío.

Si hay un principio de la escuela que no puede abandonarse, teniendo en consideración que es necesario resignificarlo, es el de la enseñanza para todos (Ramírez, 2016). Es decir, la escuela tiene que otorgarle un pupitre y, sobre todo, una formación ética e intelectual a cada uno de los individuos que conforman y le dan sentido a la sociedad y a los proyectos en común; sin que esa enseñanza para todos redunde en la uniformidad, misma que es parte de los reduccionismos que han tornado sospechosa a la modernidad. Asimismo, el fin del Sujeto de la Historia no es el acabose, al contrario, es el punto de partida para concretar la vida en común, pues ya no se trata de que la escuela le dé prioridad a una idea dominante de hombre y sociedad. En este sentido, la escuela tiene que adecuarse a la nueva condición histórica y pensar más allá de la burguesía o el proletariado:

El ideal de Comenio se cumplió, pero solo en parte, la escolarización respondió al proyecto pedagógico de la modernidad, su diseño y configuración expresa un deseo por el 
orden y la sistematización de los procesos educativos para motivar el progreso, nociones que son propias de la mentalidad burguesa y su relato científico. (López, 2016, p. 48)

La ciencia no está bajo la lupa, los señalamientos y las sospechas son en relación al cientificismo, en la medida que éste asocia al conocimiento únicamente con la ciencia (Carmona, 2007). Esta manera de entender las situaciones y las cosas es contraproducente, si lo que se quiere es detonar el conocimiento entre el yo y el otro, para que se pueda fraguar una convivencia o vida en común. En este sentido, la escuela tiene que adaptarse a las circunstancias y fomentar una educación con conocimientos prácticos (éticos y morales).

Se le ha asignado y se le siguen asignando tareas colosales a la escuela, por ello es necesaria la prudencia al momento de hacerle peticiones, si no se quiere repetir los errores del pasado. Por otro lado, la escuela puede propiciar que la conversación sea un hábito más allá de sus aulas: "Lo que hace que algo sea una conversación no es el hecho de habernos enseñado algo nuevo, sino que hayamos encontrado en el otro algo que no habíamos encontrado aún en nuestra experiencia del mundo" (Carmona, 2007, p. 150). El hecho de escuchar al otro ocasiona que el yo deje su solipsismo, y también hace factible el respeto, la solidaridad.

Si el hombre en su dimensión individual y social, puede modificar cualitativamente a la cultura y la civilización, es porque está dispuesto a abrirse a los encuentros y hasta los desencuentros, pero si se mantiene la atomización y el aislamiento como consigna en esta etapa de la modernidad, pues por más modificaciones que se le hagan a la escuela, no se podrá cambiar nada. Sin embargo, se tiene que intentar desmontar y sepultar al desencanto, ya que el hombre merece una vida en la que sus pensamientos y acciones signifiquen al mundo, y no vayan a desembocar al absurdo y al vacío.

\section{Conclusiones:}

El esbozo de la modernidad y su repercusión en el pensamiento-acción da la posibilidad de inquirir ¿se puede cambiar el decurso de los acontecimientos? ¿En dónde sustentarse, si es que en realidad 
los esfuerzos son energía desperdiciada? Es difícil destruir o renunciar a la modernidad, pues a pesar de los pesares, es la referencia en cuanto a lo que se dice y lo que se hace. Así pues, la modernidad sigue siendo el relato dominante, en el sentido de que se le asume a modo de guía o se le confronta, pero no pasa desapercibido.

Es sensato denunciar y distanciarse de la razón instrumental. Sin embargo, abdicar de la razón es un disparate, en el sentido de quedarse desprotegido, pues sin juicios ya no hay sentido, ni para el sinsentido. Además, si se aspira a modificar el modo en el cual llevar a cabo la convivencia, es necesario que se converse lo más razonablemente posible, para que se puedan establecer objetivos que convoquen e interpelen a los que concurren y se encuentran siendo en el espacio socio-histórico.

Si las explicaciones ya no pueden ser totales, en el sentido de que designen una única manera de comprender y experimentar el mundo; las posibles soluciones tampoco pueden ser totales, baste como ejemplo, la reflexión a propósito de la escuela. Es decir, si aquí se ha pensado la convivencia a través de la escuela, no es porque se considere que solamente la escuela tiene la capacidad de detonarla; pero no se puede demeritar la cualidad de enseñanza que la escuela tiene, sobre todo, si no se tiene una propuesta viable para sustituirla. Ahora bien, la enseñanza escolar es histórica y se adapta a las circunstancias, esa característica es la que permite seguir teniendo confianza en la escuela, para que coadyuve a la orientación del hombre en esta etapa de la modernidad.

Si se quieren derruir los reduccionismos es importante que el pensamiento no caiga en ellos. En este sentido, la escuela no sólo tiene que enseñar y detonar la convivencia, pues la escuela no tiene que renunciar a la enseñanza y formación del intelecto. Ahora bien, la añoranza es que la escuela forme de manera integral, pero no como slogan para atraer consumidores, sino que realmente intente contribuir para que los educandos sean capaces de comprender y generar conocimientos, además, de estar en condiciones para distinguir éticamente y en el presente el bien del mal. 
¿Hasta dónde es oportuno buscar la distinción del bien y del mal? ¿El afán de distinguir el bien del mal hoy, puede ser considerado parte del pensamiento moderno? Aquí se retoma el argumento de que las preguntas no siempre son correctas, pero no por ello son infructuosas, ya que trasladan al pensamiento hacia la exploración de vetas que antes no tenía consideradas. En este sentido, la distinción del bien y del mal, puede permitir clarificar y expresar los sentidos de una época desencantada, pero no por ello ajena de violencia, ésta es contraproducente en aras de buscar establecer la convivencia entre el yo-otro.

Si se considera que la modernidad tiene un espíritu crítico e inventivo, la tarea para los modernos de hoy seria resignificarlo, con ello también se tiene que resignificar su institución pedagógica, o sea, la escuela. Es decir, para que no se agote la confianza en la razón, ni en la capacidad de enseñar que tiene la escuela, ambas tienen que clarificar el escenario y perfilar el rumbo a seguir individual y colectivamente. Empero, la razón y la escuela tienen que dejar de ser comparsas de los reduccionismos: científicos, sociales, éticos.

La intervención en aras de hacer genuinamente compartido el mundo para el yo-otro, es lo que puede propiciar el fin del desencanto. Pero, esa posibilidad que se vislumbra en la intervención a través del pensamiento-acción no puede quedarse sólo en añoranza. Asimismo, cabe recordar que, el empeño y el esfuerzo no son suficientes, aunque sin ellos se vuelve imposible la proyección sensata respecto a otro modo de ser en el mundo, en el entendido de que se quiere superar los reduccionismos y absurdos de la modernidad.

\section{Referencias}

Bauman, Z. (2009). Ética posmoderna. Madrid, España. Siglo XXI Editores.

Benjamin, W. (2008). Tesis sobre la historia y otros fragmentos. Distrito Federal, México: Ítaca/UACM.

Carmona, M. (2007). La educación y la crisis de la modernidad. Hacia una educación humanizadora. Revista de Artes y Humanidades UNICA, 8 (19), 134-157. Recuperado de https://www.redalyc.org/pdf/1701/170118451008.pdf 
Echeverría, B. (2008). Introducción. Benjamin, la condición judía y la política. En: Tesis sobre la historia y otros fragmentos. Distrito Federal, México: Ítaca/UACM.

Gellner, E. (2001). Naciones y nacionalismo. Madrid, España: Alianza Editorial.

Giddens, A. (1994). Consecuencias de la modernidad. Madrid, España: Alianza Editorial.

Herramienta. (2020). La crisis de la escuela: una reflexión en torno al problema de su especificidad.

Recuperado de https://herramienta.com.ar/articulo.php?id=874

Horkheimer, M. (1973). Crítica de la razón instrumental. Buenos Aires, Argentina: SUR.

Levinas, E. (2008). Ética e infinito. Madrid, España: Machado Ediciones.

López, L. (2016). La escolarización: el proyecto pedagógico de Comenio para la modernidad. Revista de Ciencias de la Educación ACADEMICUS, 1(8), 46-49. Recuperado de http://www.ice.uabjo.mx/media/15/2017/05/Art8 5.pdf

Löwy, M; y Sayre, R. (2008). Rebelión y melancolía. El romanticismo a contracorriente de la modernidad. Buenos Aires, Argentina: Ediciones Nueva Visión.

Mariano, M.; Conforti, M. A. y Casado, N. (2012). La modernidad residual. Sobre educación, escuela y comunidad. Las representaciones del "detrás de las vías". Questión, 1(35), 358-371. Recuperado de https://perio.unlp.edu.ar/ojs/index.php/question/article/view/1575/1374

Noro, J. (2006). Las escuelas atraviesan una crisis de sentido. Hay que abolir la escolaridad moderna para crear una nueva estructura acorde con los tiempos. Tendencias de la educación, 21. Recuperado de https://www.tendencias21.net/Las-escuelas-atraviesan-una-crisis-desentido a950.html

Tello, C. (2010). La escuela en tiempos de crisis de la modernidad. Odiseo Revista electrónica de pedagogía. Recuperado de https://odiseo.com.mx/marcatexto/la-escuela-en-tiempos-decrisis-de-la-modernidad/

Rancière, J. (2010). El espectador emancipado. Buenos Aires, Argentina: Manantial.

Rancière, J. (2017). Tiempos modernos. Ensayos sobre la temporalidad en el arte y la política. Santander, España: Shangrila ediciones. 
Rivas, R. (2013). Ensayos críticos sobre la posmodernidad. Crisis del sentido de la vida y la historia. Distrito Federal, México: Universidad Intercontinental.

Spinoza, B. (2011). Ética demostrada según el orden geométrico. Madrid, España: Gredos.

Torres, A. (1997). Escuela y comunidad. Modernidad y nuevos sentidos de lo comunitario. Pedagogía y saberes, 10, 5-14. Recuperado de https://revistas.pedagogica.edu.co/index.php/PYS/article/view/6211/5163

Touraine, A. (1994). Crítica de la modernidad. Buenos Aires, Argentina: Fondo de Cultura Económica.

Vázquez, J. (2000). Educación y modernidad. Entre la utopía y la burocracia de Eduardo Terrén. Política y sociedad, 35, 183-184. Recuperado de http://webcache.googleusercontent.com/search?q=cache:VETELMKVLp0J:ri.ibero.mx/handl e/ibero/1365+\&cd=2\&hl=es-419\&ct=clnk\&gl=mx. 